(c) American Dairy Science Association, 2007.

\title{
Changes in Measures of Biotin Status Do Not Reflect Milk Yield Responses When Dairy Cows Are Fed Supplemental Biotin
}

\author{
G. Ferreira, W. P. Weiss, ${ }^{1}$ and L. B. Willett \\ Department of Animal Sciences, Ohio Agricultural Research and Development Center, The Ohio State University, Wooster 44691
}

\begin{abstract}
A sensitive indicator of biotin status for lactating dairy cows is necessary to understand factors that affect milk yield responses to biotin supplementation. 3-Hydroxyisovaleric acid (3HIA) is an alternative metabolite in the pathway of Leu catabolism when the biotin-dependent enzyme methylcrotonyl-coenzyme A carboxylase is limiting. We evaluated urinary excretion of 3HIA as a determinant of biotin status in lactating dairy cows. We hypothesized that high-producing cows would have a greater biotin requirement and excrete more 3 HIA than low-producing cows and that biotin supplementation would decrease 3HIA excretion. Twenty high-producing and 20 low-producing Holstein cows (43 \pm 5 and $23 \pm 4 \mathrm{~kg} / \mathrm{d}$ of milk, respectively) were fed diets that contained either 0 or $0.96 \mathrm{mg} / \mathrm{kg}$ of supplemental biotin. On d 16 cows were given an intraruminal infusion of $1.4 \mathrm{~mol}$ of isovaleric acid and urine was sampled. Biotin supplementation did not affect basal urinary excretion of 3HIA. The infusion of isovaleric acid increased urinary excretion of 3HIA (maximum at $8 \mathrm{~h}$ after infusion), but biotin supplementation did not attenuate this increase. The increase in urinary 3HIA excretion was less for low-producing cows than for highproducing cows. Biotin increased yields of milk and milk components in high-producing cows but had no effect in low-producing cows. However, potential measures of biotin status (concentrations of avidin-binding substances in the plasma, milk, and urine, and urinary 3HIA excretion) responded similarly to biotin supplementation for both high- and low-producing cows. A sensitive indicator of biotin status for lactating dairy cows is still needed.
\end{abstract}

Key words: dairy cow, biotin, 3-hydroxyisovaleric acid

\section{INTRODUCTION}

Biotin requirements for lactating dairy cows have not been established (NRC, 2001). Because it is supplied

Received July 3, 2006.

Accepted October 19, 2006.

${ }^{1}$ Corresponding author: weiss.6@osu.edu by feeds and synthesized by rumen microorganisms, clinical biotin deficiency is unlikely to occur in adult or functioning ruminants. Despite this, in several studies (Midla et al., 1998; Zimmerly and Weiss, 2001; Majee et al., 2003), but not all (Fitzgerald et al., 2000; Rosendo et al., 2004), biotin supplementation was shown to increase the milk yield of lactating dairy cows. The response in milk yield could be affected by several factors, such as diet composition and lactation stage, but also may depend on the biotin status of the cow. To improve our understanding of the effects of biotin supplementation on milk yield, a sensitive indicator of biotin status for lactating dairy cows is necessary.

Concentrations of avidin-binding substances (ABS) in the blood and milk have been used as measures of biotin status in lactating dairy cows. In addition to biotin, ABS include biotin metabolites, such as bisnorbiotin and biotin sulfoxide, that may lack vitamin activity. In humans, biotin accounts for approximately 50 and $70 \%$ of the total ABS in serum (Mock et al., 1995) and milk (Mock et al., 1997a), respectively.

Mock et al. (1997b) evaluated different determinants of biotin status in humans and concluded that urinary excretion of 3-hydroxyisovaleric acid (3HIA) is an early and sensitive indicator of marginal biotin deficiency. 3 -Hydroxyisovaleric acid is the alternative metabolite formed from 3-methylcrotonyl-coenzyme A (CoA) when the activity of a biotin-dependent enzyme, methylcrotonyl-CoA carboxylase (MCC), is limiting. Under the assumption that the activity of MCC is limiting in dairy cows, we hypothesized that urinary excretion of 3HIA would decrease when biotin was supplemented. We also hypothesized that high-producing cows would have a greater need for biotin than low-producing cows, and consequently, that production responses to biotin supplementation would be greater, concentrations of ABS in biological fluids would be lower, and urinary excretion of 3HIA would be greater for high-producing than for low-producing cows. The objective of this study was to determine whether common measures of biotin status were related to milk yield responses when dairy cows were fed supplemental biotin. 
Table 1. Ingredients and nutrient composition of the basal diet ${ }^{1}$

\begin{tabular}{lc}
\hline Item & \% of dietary DM \\
\hline Ingredient & \\
Corn silage & 19.3 \\
Alfalfa silage & 21.0 \\
Corn grain, dry and ground & 21.9 \\
Corn gluten meal & 10.0 \\
Soybean hulls & 16.9 \\
Soybean meal, 44\% CP & 8.0 \\
Fat, animal and vegetable blend & 1.0 \\
Urea & 0.1 \\
Sodium bicarbonate & 0.8 \\
Minerals and vitamins ${ }^{2}$ & 0.1 \\
Chemical analysis & \\
CP & 20.7 \\
NDF & 33.0 \\
Starch & 24.6 \\
Long-chain fatty acids & 4.0 \\
\hline
\end{tabular}

${ }^{1}$ Diet with supplemental biotin contained $0.0048 \%$ of biotin premix ( $20 \mathrm{mg} / \mathrm{g}$ of Rovimix H-2; DSM Nutritional Products Inc., Parsippany, $\mathrm{NJ}$ ), which replaced a similar amount of corn gluten meal.

${ }^{2}$ The diet contained $0.2 \%$ dicalcium phosphate, $0.36 \%$ limestone, $0.01 \%$ magnesium oxide, $0.21 \%$ trace mineral salt, $0.03 \%$ sodium selenate $(200 \mathrm{mg} / \mathrm{kg}), 0.0024 \%$ zinc sulfate, $0.0012 \%$ copper sulfate, $3,300 \mathrm{IU} / \mathrm{kg}$ of vitamin $\mathrm{A}, 810 \mathrm{IU} / \mathrm{kg}$ of vitamin $\mathrm{D}$, and $22 \mathrm{IU} / \mathrm{kg}$ of vitamin E.

\section{MATERIALS AND METHODS}

\section{Animals, Diets, and Ruminal Infusion}

All procedures involving animals were approved by the Agricultural Animal Care and Use Committee of The Ohio State University. Twenty multiparous highproducing ( $43 \pm 5 \mathrm{~kg} / \mathrm{d}$ of milk yield and $136 \pm 56 \mathrm{DIM}$ at the beginning of the experiment) and 20 multiparous low-producing Holstein cows $(23 \pm 4 \mathrm{~kg} / \mathrm{d}$ of milk yield and $267 \pm 53 \mathrm{DIM}$ ) were used. In the high-producing group, only 4 cows were pregnant (average day of gestation $=32$ for animals that were pregnant). In the lowproducing group, 16 cows were pregnant (average day of gestation for pregnant cows $=131$ ). Cows within the same production group were blocked by milk yield (average of the 7-d period before the beginning of the experiment) and randomly assigned to 1 of 2 treatments. Diets (Table 1) contained either 0 or $0.96 \mathrm{mg}$ of supplemental biotin/kg of DM. The concentration of supplemental biotin was selected to supply $20 \mathrm{mg} / \mathrm{d}$ based on an estimated DMI of $21 \mathrm{~kg} / \mathrm{d}$. The diet was formulated to meet nutrient requirements (NRC, 2001) for a 650$\mathrm{kg}$ lactating dairy cow producing $40 \mathrm{~kg}$ of milk/d. High proportions of grain in the substrate have been shown to decrease microbial biotin synthesis in vitro (Abel et al., 2001); therefore, we formulated the basal diet to contain a high proportion of concentrate $(60 \% \mathrm{DM}$ basis). Corn gluten meal ( $75 \%$ RUP) was the main protein source because it has high concentrations of Leu, the substrate for MCC. Supplemental biotin (Rovimix
Biotin; DSM Nutritional Products Inc., Parsippany, NJ) was supplied in the pelleted concentrate mix. Cows were housed in individual tie stalls and fed once daily $(0400 \mathrm{~h})$. Diets were offered ad libitum ( $\sim 5 \%$ feed refusals, as-fed basis) as mixed rations. The amount of feed offered and refused was measured daily. Diets were adjusted weekly for changes in ingredient DM concentration. Cows were milked twice daily (0200 and 1300 h) and milk weights were recorded electronically at each milking. The average from the 14 daily milk yields was used as the value for milk yield. Cows were weighed on $\mathrm{d} 14$ at $0800 \mathrm{~h}$.

On d 16, cows were given a pulse intraruminal dose of $1.4 \mathrm{~mol}$ of isovaleric acid (IVA; the dose and sampling schedule used were based on a small preliminary trial). The solution of IVA was prepared on $d 15$ by mixing $150 \mathrm{~mL}$ of IVA (TCI America, Inc., Portland, OR) with $3.5 \mathrm{~L}$ of distilled water. The solution was adjusted to $\mathrm{pH} 6.2$ by adding $\sim 50 \mathrm{~g}$ of $\mathrm{NaOH}$. Intraruminal infusions were done at $0800 \mathrm{~h}$ by stomach tubing and took approximately 2 min per cow.

\section{Sample Collection and Analysis}

Samples of feeds and feed refused were collected once weekly. Aliquots of feed and feed refusal samples were dried in a forced-air oven for $24 \mathrm{~h}$ at $100^{\circ} \mathrm{C}$. A second aliquot of feed was stored at $-20^{\circ} \mathrm{C}$ until analysis. Forage samples were lyophilized and all feed samples were ground to pass through a 1-mm screen of a Wiley mill (Arthur H. Thomas, Philadelphia, PA). Ground samples were analyzed for DM $\left(24 \mathrm{~h}\right.$ at $\left.100^{\circ} \mathrm{C}\right), \mathrm{NDF}\left(\right.$ Ankom $^{200}$ Fiber Analyzer; Ankom Technology, Fairport, NY) with sodium sulfite and $\alpha$-amylase (Ankom Technology), CP (Kjeldahl, $\mathrm{N} \times 6.25$; AOAC, 2000), starch (Weiss and Wyatt, 2000), and long-chain fatty acids (Sukhija and Palmquist, 1988). Samples of rumen fluid were collected on d 15 via stomach tube and analyzed for VFA concentrations (Zimmerly and Weiss, 2001). Milk samples (a.m. and p.m. milkings) were collected on d 7 and 14 for determination of milk fat, true protein, and lactose concentrations with a B2000 Infrared Analyzer (Bentley Instruments, Chaska, MN) by DHI Cooperative, Inc. (Columbus, $\mathrm{OH}$ ). Milk yields from d 7 and 14 were used to calculate yields of milk components.

An additional milk sample was collected on d 15 (p.m. milking) for determination of the ABS concentration. This sample was stored at $4^{\circ} \mathrm{C}$ immediately after collection. Within $4 \mathrm{~h}$ after collection, milk samples were warmed in a water bath at $39^{\circ} \mathrm{C}$ for $10 \mathrm{~min}$ and homogenized by repeated ( $5 \times$ ) pouring into a beaker. A $10-\mathrm{mL}$ aliquot of homogenized whole milk was centrifuged at $20,000 \times g$ for $20 \mathrm{~min}$ at $4^{\circ} \mathrm{C}$. After removing the fat layer, skim milk was decanted and stored at $-20^{\circ} \mathrm{C}$ until 
ABS analysis. The concentration of ABS in skim milk (1:400 and 1:800 dilution for the control and biotin treatments, respectively) was determined by a singlestep competitive enzyme-binding assay (Ridascreen Biotin kit; R-Biopharm GmbH, Darmstadt, Germany). Concentrations of ABS are reported on a whole-milk basis, and were calculated as the concentration of ABS in skim milk (nmol/L) multiplied by the ratio of skim milk to whole milk.

Blood samples were collected at $0800 \mathrm{~h}$ of $\mathrm{d} 15$ by venipuncture of the coccygeal vein, immediately transferred into heparinized tubes, stored in ice, and transferred to the laboratory. Plasma was obtained after centrifugation of blood at $4,000 \times g$ for $30 \mathrm{~min}$ and stored at $-20^{\circ} \mathrm{C}$ until $\mathrm{ABS}$ analysis. Concentrations of $\mathrm{ABS}$ in plasma (1:10 dilution) were determined as described above.

Urine samples $(\sim 300 \mathrm{~mL})$ were collected by vulva stimulation at $0,8,12,24$, and $48 \mathrm{~h}$ postinfusion. Urine samples $(20 \mathrm{~mL})$ were centrifuged at $4,000 \times g$ for 20 min, decanted, and stored at $4^{\circ} \mathrm{C}$ until analysis for creatinine (Di Giorgio, 1974) and 3HIA concentrations. All samples were analyzed within 1 wk of collection. Urine samples were extracted as described by Truscott et al. (1979), with one additional acidic extraction with ethyl acetate. To facilitate the separation of phases, each extraction was performed after a 3-min centrifugation at $20,000 \times$ g. A $1-\mathrm{mL}$ aliquot of the extract was dried at room temperature under a stream of $\mathrm{N}_{2}$. The dried extract was solubilized and derivatized as described by Mock et al. (2004), using $50 \mu \mathrm{L}$ of pyridine and $50 \mu \mathrm{L}$ of bis(trimethylsilyl)trifluoroacetamide in 1\% trimethylchlorosilane (Alltech Associates, Inc., Deerfield, IL). The GC-MS analysis was performed using an HP 6890 gas chromatograph with a $30 \mathrm{~m} \times 0.25 \mathrm{~mm}$ HP-5MS capillary column connected to an HP 5973 mass selective detector (Agilent Technologies Inc., Palo Alto, CA). The oven temperature was programmed as described by Mock et al. (1989). For quantification, 3HIA (55453 Fluka; Sigma Diagnostics, St. Louis, MO) was used as an external standard. To improve resolution, the mass selective detector was set in the selected ion-monitoring mode to detect the molecular-ion peak at $\mathrm{m} / z 131$. The recovery of 3HIA from urine after extraction was $96 \%$. The intraassay coefficient of variation for measurement of 3HIA was $6.2 \%$. Excretion of 3HIA was expressed as millimoles of 3HIA per mole of creatinine. Concentrations of ABS in urine (1:1000 dilution) were determined as described above.

\section{Statistical Analyses}

Ten cows per treatment were used in this study. One low-producing and one high-producing cow that were assigned to the control and biotin diets, respectively, were removed from the experiment because of health problems (right-displaced abomasum and undefined infection, respectively). Data from these cows were not used for statistical analyses. We could not obtain rumen fluid from one low-producing cow consuming the control diet, resulting in 8 cows for that treatment for rumen fluid data. Production measures, ABS concentrations in fluids, and baseline urinary excretion of 3HIA were analyzed as a randomized complete block design using the MIXED procedure of SAS (SAS Institute, 2004). The model included the effects of block (random, $\mathrm{df}=$ 9 ) and treatment (fixed, $\mathrm{df}=3$ ), and the residual error. To test our hypotheses, the degrees of freedom associated with the treatment were partitioned into 3 single degree of freedom contrasts: 1 ) effect of biotin supplementation in low-producing cows; 2) effect of biotin supplementation in high-producing cows; and 3) overall effect of production (all high-producing cows vs. all lowproducing cows). To adjust for differences in milk yield among treatment groups before the experiment started, average daily milk yield of the 7-d period before the experiment started was calculated for each cow. That value was subtracted from the respective productiongroup average milk yield and included in the statistical model as a covariate for production measures. The effect of IVA infusion on 3HIA excretion was analyzed as a randomized complete block design with repeated measures using the MIXED procedure of SAS. The model included the effects of block (random, $\mathrm{df}=9$ ) and treatment (fixed, $\mathrm{df}=3$ ), the whole plot error (random, $\mathrm{df}=$ 8 ), the effect of time (fixed, $\mathrm{df}=4$ ), the interaction of time and treatment (fixed, $\mathrm{df}=12$ ), and the residual error (random, $\mathrm{df}=68$ ). The heterogeneous compound symmetry covariance structure was selected for analysis with repeated measures based on Akaike's information criterion. The data following IVA infusion were also analyzed using the model described for production measures within each time point. Treatment degrees of freedom were partitioned as described above.

\section{RESULTS}

\section{Production Measures}

As anticipated, DMI and yields of milk and milk components were greater $(P<0.01)$ and BW and the concentration of milk protein were lower $(P<0.02)$ for the high-producing cows than for the low-producing group (Table 2). Of the greatest interest were the effects of biotin supplementation within production groups. For low-producing cows, no differences were observed between cows on the control and biotin-supplemented diets for any production measure, but biotin supplementation increased yields of milk, milk fat, lactose (all 
Table 2. Production measures of low- and high-producing cows consuming a diet with either 0 (Control) or $0.96 \mathrm{mg} / \mathrm{kg}$ of DM of supplemental biotin (Biotin)

\begin{tabular}{|c|c|c|c|c|c|c|c|c|}
\hline \multirow[b]{2}{*}{ Item } & \multicolumn{2}{|c|}{ Low-producing } & \multicolumn{2}{|c|}{ High-producing } & \multirow[b]{2}{*}{ SEM $^{1}$} & \multicolumn{3}{|c|}{ Contrasts, ${ }^{2} P<$} \\
\hline & Control & Biotin & Control & Biotin & & 1 & 2 & 3 \\
\hline BW, kg & 718 & 717 & 634 & 629 & 29 & 0.96 & 0.87 & 0.01 \\
\hline DMI, kg/d & 21.6 & 21.1 & 23.9 & 25.0 & 0.78 & 0.62 & 0.29 & 0.01 \\
\hline Milk yield, $\mathrm{kg} / \mathrm{d}$ & 24.1 & 24.2 & 41.8 & 44.5 & 0.94 & 0.98 & 0.05 & 0.01 \\
\hline Milk fat, $\mathrm{g} / \mathrm{kg}$ & 37.0 & 37.9 & 34.7 & 39.5 & 0.19 & 0.74 & 0.11 & 0.88 \\
\hline Fat yield, kg/d & 0.86 & 0.93 & 1.41 & 1.78 & 0.60 & 0.58 & 0.01 & 0.01 \\
\hline Milk protein, g/kg & 34.5 & 33.4 & 29.6 & 29.1 & 0.09 & 0.35 & 0.67 & 0.01 \\
\hline Protein yield, $\mathrm{kg} / \mathrm{d}$ & 0.81 & 0.82 & 1.21 & 1.31 & 0.04 & 0.91 & 0.06 & 0.01 \\
\hline Milk lactose, $\mathrm{g} / \mathrm{kg}$ & 47.6 & 47.6 & 48.1 & 49.0 & 0.09 & 0.96 & 0.45 & 0.23 \\
\hline Lactose yield, kg/d & 1.12 & 1.16 & 1.97 & 2.22 & 0.07 & 0.71 & 0.01 & 0.01 \\
\hline
\end{tabular}

\footnotetext{
${ }^{1}$ Low-producing cows on the control treatment and high-producing cows on the biotin treatment, $\mathrm{n}=9$ per treatment; $\mathrm{n}=10$ for the other 2 treatments. The SEM shown is for treatments with $\mathrm{n}=9$. To calculate SEM for treatments with $\mathrm{n}=10$, multiply SEM by 0.949 .

${ }^{2}$ Contrasts: 1 = effect of biotin supplementation to low-producing cows; 2 = effect of biotin supplementation to high-producing cows; 3 = low-producing vs. high-producing cows.
}

$P<0.05)$, and milk protein $(P<0.06)$ in high-producing cows.

\section{VFA in Rumen Fluid}

The proportion of acetate was lower $(P<0.01)$ and the proportion of propionate was greater $(P<0.01)$ in high-producing cows than in low-producing cows, which caused the acetate-to-propionate ratio to be higher ( $P$ $<0.01$ ) for low-producing cows (Table 3). Biotin supplementation did not influence the molar proportions of most VFA in either low- or high-producing cows. The exception was valerate, which was reduced when supplemental biotin was given to low-producing cows. Numerically, the difference was small and the biological significance of this response is probably minor.

\section{Measures of Biotin Status}

Cows fed supplemental biotin in both production groups had higher $(P<0.01)$ concentrations of ABS in the plasma, milk, and urine, but no differences were observed between production groups (Table 4). The basal (i.e., preinfusion of IVA) urinary concentration of 3HIA was not affected by treatment. Infusing $1.4 \mathrm{~mol}$ of IVA substantially increased urinary 3HIA $(P<0.01)$, which was greatest $8 \mathrm{~h}$ after infusion (Figure 1). Biotin supplementation did not attenuate this increase in either low-producing or high-producing cows. Peak concentrations $(8 \mathrm{~h}$ postinfusion) were greater $(P<0.05)$ for high-producing cows than low-producing cows and tended to be greater $(P<0.08)$ at $12 \mathrm{~h}$ postinfusion.

\section{DISCUSSION}

We hypothesized that high-producing cows would have a greater demand for biotin than would low-producing cows. In agreement with our expectations, biotin supplementation increased yields of milk and milk components in high-producing cows but not in low-producing cows. This observation agrees with results from

Table 3. Volatile fatty acids (mol/100 mol of VFA) in rumen fluid from low- and high-producing cows fed a diet with either 0 (Control) or $0.96 \mathrm{mg} / \mathrm{kg}$ of DM of supplemental biotin (Biotin)

\begin{tabular}{|c|c|c|c|c|c|c|c|c|}
\hline \multirow[b]{2}{*}{ Item } & \multicolumn{2}{|c|}{ Low-producing } & \multicolumn{2}{|c|}{ High-producing } & \multirow[b]{2}{*}{ SEM $^{1}$} & \multicolumn{3}{|c|}{ Contrasts, ${ }^{2} P<$} \\
\hline & Control & Biotin & Control & Biotin & & 1 & 2 & 3 \\
\hline Acetate & 61.1 & 62.5 & 58.5 & 58.2 & 1.26 & 0.34 & 0.84 & 0.01 \\
\hline Propionate & 21.3 & 20.3 & 24.5 & 24.7 & 1.40 & 0.54 & 0.89 & 0.01 \\
\hline Butyrate & 13.3 & 13.2 & 12.7 & 13.0 & 0.67 & 0.90 & 0.74 & 0.56 \\
\hline Isobutyrate & 0.8 & 0.9 & 0.8 & 0.7 & 0.22 & 0.54 & 0.41 & 0.29 \\
\hline Valerate & 2.3 & 1.9 & 2.2 & 2.2 & 0.21 & 0.02 & 0.70 & 0.64 \\
\hline Isovalerate & 1.2 & 1.2 & 1.3 & 1.1 & 0.17 & 0.82 & 0.37 & 0.85 \\
\hline Acetate:propionate & 2.94 & 3.15 & 2.44 & 2.47 & 0.25 & 0.42 & 0.88 & 0.01 \\
\hline
\end{tabular}

${ }^{1}$ For low-producing cows on the control treatment, $\mathrm{n}=8$; for high-producing cows on the biotin treatment, $\mathrm{n}=9 ; \mathrm{n}=10$ for the other 2 treatments. The SEM shown is for the treatment with $\mathrm{n}=9$. To calculate SEM for treatments with $n=10$, multiply SEM by 0.949 . To calculate SEM for the treatment with $n=8$, multiply SEM by 1.061.

${ }^{2}$ Contrasts: 1 = effect of biotin supplementation on low-producing cows; 2 = effect of biotin supplementation on high-producing cows; 3 = low-producing vs. high-producing cows. 
Table 4. Concentrations of avidin-binding substances (ABS) and basal (i.e., preinfusion) urinary concentration of 3-hydroxyisovaleric acid (3HIA) of low- and high-producing cows fed a diet containing either 0 (Control) or $0.96 \mathrm{mg} / \mathrm{kg}$ of DM of supplemental biotin (Biotin)

\begin{tabular}{|c|c|c|c|c|c|c|c|c|}
\hline \multirow[b]{2}{*}{ Item } & \multicolumn{2}{|c|}{ Low-producing } & \multicolumn{2}{|c|}{ High-producing } & \multirow[b]{2}{*}{$\mathrm{SEM}^{1}$} & \multicolumn{3}{|c|}{ Contrasts, ${ }^{2} P<$} \\
\hline & Control & Biotin & Control & Biotin & & 1 & 2 & 3 \\
\hline Plasma ABS, nmol/L & 4.3 & 7.8 & 4.4 & 7.6 & 0.47 & 0.01 & 0.01 & 0.93 \\
\hline Milk ABS, nmol/L & 141.7 & 471.6 & 145.3 & 504.8 & 32.6 & 0.01 & 0.01 & 0.57 \\
\hline Urine ABS, $\mu \mathrm{mol} / \mathrm{mol}$ of creatinine & 94.8 & 201.1 & 93.4 & 177.0 & 14.1 & 0.01 & 0.01 & 0.34 \\
\hline Urine $3 \mathrm{HIA}, \mathrm{mmol} / \mathrm{mol}$ of creatinine & 66.8 & 70.1 & 68.5 & 67.2 & 10.2 & 0.80 & 0.92 & 0.95 \\
\hline
\end{tabular}

\footnotetext{
${ }^{1}$ Low-producing cows on the control treatment and high-producing cows on the biotin treatment, $\mathrm{n}=9$ per treatment; $\mathrm{n}=10$ for the other 2 treatments. The SEM shown is for treatments with $\mathrm{n}=9$. To calculate SEM for treatments with $\mathrm{n}=10$, multiply SEM by 0.949 .

${ }^{2}$ Contrasts: 1 = effect of biotin supplementation on low-producing cows; 2 = effect of biotin supplementation on high-producing cows; 3 = low-producing vs. high-producing cows.
}

most studies using low-producing (Fitzgerald et al., 2000) and high-producing cows (Midla et al., 1998; Zimmerly and Weiss, 2001; Majee et al., 2003). Reasons for the lack of response to biotin supplementation by highproducing cows $(35 \mathrm{~kg} / \mathrm{d}$ ) in another study (Rosendo et al., 2004) are unclear.

The mechanism by which biotin supplementation increases milk yield is still unknown. Because certain cellulolytic bacteria require biotin for growth (Scott and Dehority, 1965), increased growth of cellulolytic bacteria in response to biotin supplementation could possibly have increased DM digestibility and, consequently, milk yield. However, Majee et al. (2003) reported that biotin supplementation did not affect DM or fiber total tract digestibility in high-producing dairy cows. Also, an increase in the population of cellulolytic bacteria

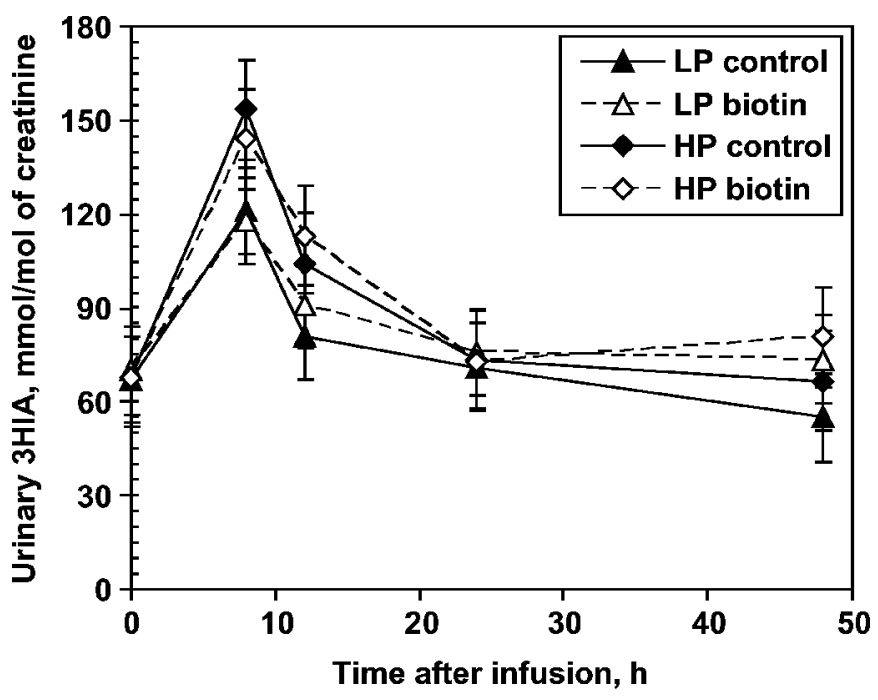

Figure 1. Urinary 3-hydroxyisovaleric acid (3HIA) of lactating dairy cows after an intraruminal infusion of $1.4 \mathrm{~mol}$ of isovaleric acid (3-methyl isomer). High-producing (HP) and low-producing (LP) cows were fed a diet containing either 0 (control) or $0.96 \mathrm{mg} / \mathrm{kg}$ of DM (biotin) of supplemental biotin. Values are means \pm SEM. would likely increase the molar proportions of acetate in rumen fluid. Biotin supplementation did not affect the molar proportions of acetate and propionate (Table $3)$. This last observation is consistent with previous observations (Zimmerly and Weiss, 2001).

Biotin supplementation increased the lactose yield by high-producing cows (Table 2). This observation is consistent with the data of Majee et al. (2003). Neither Zimmerly and Weiss (2001) nor Rosendo et al. (2004) reported milk lactose concentrations or yields. Because lactose secretion is the main determinant of milk volume, the response in milk yield to biotin supplementation may be related to increased lactose secretion, presumably by an increased supply of glucose to the mammary gland. Zimmerly and Weiss (2001) hypothesized that glucose production could be increased by biotin supplementation. Pyruvate carboxylase and propionylCoA carboxylase are 2 biotin-dependent enzymes involved in gluconeogenesis. Biotin supplementation was found to increase the activity of liver pyruvate carboxylase in lactating dairy cows (Ferreira and Weiss, 2007).

Biotin supplementation increased fat yield by highproducing cows (Table 2). This increase may be indirectly related to an increase in gluconeogenesis in the liver. Increased glucose supply to the mammary gland may increase glucose oxidation through the pentose phosphate pathway, thereby increasing the availability of reducing equivalents for fatty acid synthesis. Another explanation for the increased fat yield in high-producing cows may be related to a direct effect of biotin supplementation on fatty acid synthesis by increasing the activity of acetyl-CoA carboxylase. Zimmerly and Weiss (2001) and Rosendo et al. (2004) observed no effect of biotin supplementation on fat yield by lactating dairy cows in early lactation (less than $100 \mathrm{~d}$ after parturition). However, the lack of response in fat yield to biotin supplementation in these studies may be related to the inhibition of de novo synthesis of fatty acids because of the negative energy balance observed during early 


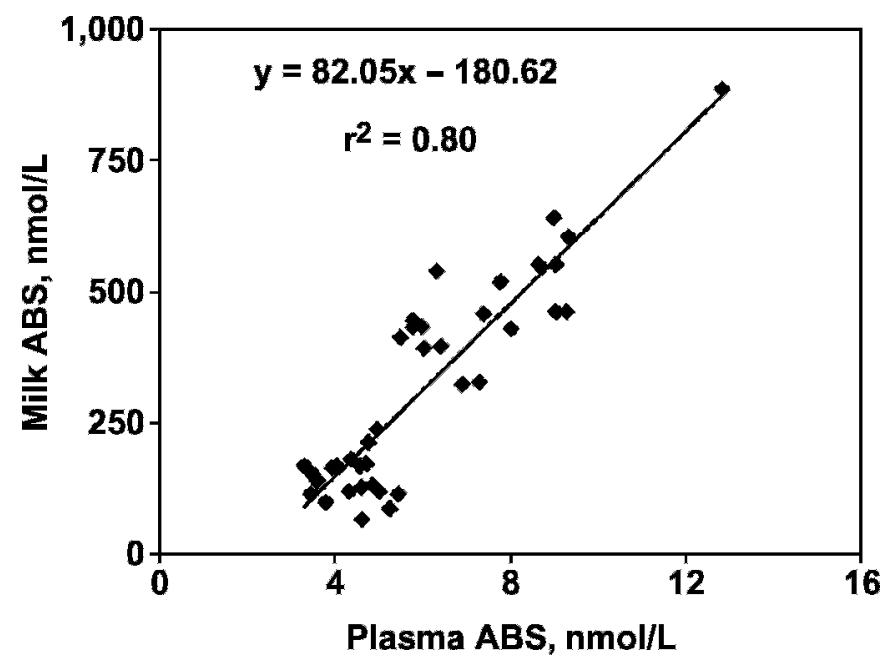

Figure 2. Relationship between the concentrations of avidin-binding substances (ABS) in the milk and plasma of lactating dairy cows.

lactation (Palmquist et al., 1993). Majee et al. (2003) observed no increase in fat yield when high-producing cows in midlactation received supplemental biotin.

Concentrations of ABS in the blood and milk are used as measures of biotin status for lactating dairy cows. Concentrations of ABS in the milk and plasma were highly and positively correlated $\left(\mathrm{r}^{2}=0.81, P<0.01\right.$; Figure 2), but milk concentrations averaged 52 times greater than plasma concentrations. The high milk concentrations of ABS imply active transport, but the relationship between plasma and milk concentrations (Figure 2) suggests that the $V_{\max }$ of the transporter was not reached in this study. In lactating women, concentrations of biotin (measured using a microbiological assay) in plasma and milk were also correlated, and milk concentrations averaged about 15 times higher than plasma concentrations (Salmenpera et al., 1985).

Based on our hypothesis that high-producing cows would have a greater demand for biotin than would low-producing cows, we expected lower concentrations of ABS in the plasma, milk, and urine for high-producing cows than for low-producing cows. Contrary to our expectations, high-producing and low-producing cows had similar ABS concentrations in the plasma and milk and similar ABS-to-creatinine ratios in the urine (Table 4). Milk production responses to biotin supplementation, however, differed between production groups. Based on this result, our data suggest that ABS concentrations in the plasma and milk and ABS-to-creatinine ratios in the urine are not sensitive determinants of biotin status in lactating dairy cows. Because we did not use a 2-step procedure (Mock et al., 1995), ABS concentrations may not reflect actual biotin concentrations. However, data from humans also showed that the concentration of actual biotin in blood is not a sensitive determinant of biotin status (Mock et al., 1997b).

Isovaleric acid, in the form of isovaleryl-CoA, is an intermediate metabolite from the catabolism of Leu. The biotin-dependent enzyme MCC is required in one intermediary step of the pathway for the complete catabolism of Leu or IVA. In the presence of MCC, 3methylcrotonyl-CoA is further metabolized to acetoacetate and acetyl-CoA. However, when the activity of MCC is limiting, 3-methylcrotonyl-CoA is alternatively metabolized to 3HIA by the action of enoyl hydratase or crotonase. The resulting 3HIA is excreted in urine (Tanaka and Isselbacher, 1970). Under the assumption that MCC activity in lactating dairy cows is limiting, we expected greater excretions of 3HIA in high-producing than in low-producing cows, but no differences were observed (Table 4). Also, urinary excretion of 3HIA did not decrease when either production group received the biotin supplement. One explanation for these observations is that 3HIA could have been formed directly from 2-ketoisocaproic acid by the action of ketoisocaproate oxygenase (Sabourin and Bieber, 1982). Even though this possibility cannot be discarded, this biotin-independent pathway implies a wasting of energy, given that IVA would be excreted without being further metabolized. Another explanation for the similar excretion of 3HIA among treatments is that the activity of MCC was adequate in these cows, and therefore the substrate load was inferior to the maximum capacity of MCC. To overload the capacity of MCC, cows were given an intraruminal infusion with $1.4 \mathrm{~mol}$ of IVA. This dose, which is equivalent to 2.8 times the mean daily absorption of IVA (3-methyl isomer), estimated from net flux from portal-drained viscera in lactating dairy cows (Reynolds et al., 1988), was sufficient to substantially increase urinary 3HIA excretion in all treatments (Figure 1). This observation suggests either that the capacity of MCC was overwhelmed or that IVA was converted to 3HIA by alternative pathways. Even though it could be involved in the conversion of 3HIA from endogenous sources (i.e., Leu catabolism), 2-ketoisocaproate oxygenase would probably not be involved in the conversion of 3HIA from exogenous sources such as infused IVA. Isovaleryl-CoA is the product of the oxidative decarboxylation of 2-ketoisocaproic acid by branched-chain AA dehydrogenase. Because this is an irreversible reaction (Block et al., 1988), exogenous IVA would probably not be converted into 3HIA through this pathway. Another alternative pathway would be the direct hydroxylation of exogenous IVA to 3HIA by IVA hydroxylase (Sabourin and Bieber, 1982). No information exists regarding IVA hydroxylase in ruminants, but if this alternative biotin-independent pathway is present, urinary 
3HIA excretion may not be a valid determinant of biotin status.

We expected biotin supplementation to attenuate the increase in urinary 3HIA after the IVA challenge. We also expected this attenuation to be greater for highproducing than for low-producing cows. Contrary to our expectations, the increase in urinary 3HIA was similar for supplemented and nonsupplemented cows. The increase in urinary 3HIA was greater for high-producing than for low-producing cows (Figure 1), suggesting that the substrate load of IVA was closer to maximum MCC capacity in high-producing than in low-producing cows. Greater loads of IVA for high-producing than for lowproducing cows may be attributed to a greater DMI (Table 2), a change in ruminal fermentation (Table 3), or a combination of both. It is tempting to suggest that a similar activity of MCC for nonsupplemented and supplemented cows explains the similar increase in the excretion of 3HIA. However, the possibility of the direct conversion of IVA to 3HIA by IVA hydroxylase should not be discarded. Regardless of the pathway, urinary 3HIA excretion was not a sensitive determinant of biotin status for lactating dairy cows under these experimental conditions.

Contrary to lactating dairy cows, in nonruminants, urinary excretion of 3HIA is a sensitive determinant of biotin status (Mock and Mock, 1992; Mock et al., 1997b). This difference may be explained from an evolutionary perspective. Isovaleric acid (an end-product of bacterial fermentation) is absorbed by the gastrointestinal tract and released into the portal vein. Daily net release of IVA (both isomers) by portal-drained viscera in growing pigs (Rerat et al., 1987) and lactating dairy cows (Reynolds et al., 1988) was approximately 1.3 and 14.9 $\mathrm{mmol} / \mathrm{kg}$ of metabolic BW, respectively. Lactating dairy cows, and likely other ruminants, must have evolved to metabolize increased loads of IVA resulting from bacterial fermentation in the rumen.

In conclusion, biotin supplementation increased milk production in high-producing cows but not in low-producing cows. The mechanism by which biotin increases milk production is still unknown. Typical measures of biotin status, such as ABS concentrations in the plasma, milk, or urine or 3HIA excretion in the urine, were not sensitive determinants of biotin status for lactating dairy cows.

\section{ACKNOWLEDGMENTS}

Appreciation is extended to Kevin Miller and the crew of the Krauss Dairy Center for day-to-day cow management and for their assistance with rumen infusions. Gratitude is extended to Donna Wyatt and Dianne Borger for their assistance in the laboratory. Salaries and research support were provided by Ohio Dairy Producers and by state and federal funds appropriated to the Ohio Agricultural Research and Development Center, The Ohio State University (Manuscript No. 10-06AS).

\section{REFERENCES}

Abel, H. J., I. Immig, C. D. Gomez, and W. Steinberg. 2001. Research note: Effect of increasing dietary concentrate levels on microbial biotin metabolism in the artificial rumen simulation system (RUSITEC). Arch. Anim. Nutr. 55:371-376.

AOAC. 2000. Official Methods of Analysis of AOAC International. 17th ed. Vols. 1 and 2. AOAC International, Gaithersburg, MD.

Block, K. P., R. P. Aftring, M. G. Buse, and A. E. Harper. 1988. Estimation of branched-chain-keto acid dehydrogenase activation in mammalian tissues. Methods Enzymol. 166:201-213.

Di Giorgio, J. 1974. Nonprotein nitrogenous constituents. Pages 503563 in Clinical Chemistry: Principles and Techniques. R. J. Henry, D. C. Cannon, and J. W. Winkelman, ed. Harper \& Row, New York, NY.

Ferreira, G., and W. P. Weiss. 2007. Effect of biotin on activity and gene expression of biotin-dependent carboxylases in the liver of dairy cows. J. Dairy Sci. 90:1460-1466.

Fitzgerald, T., B. W. Norton, R. Elliott, H. Podlich, and O. L. Svendsen. 2000. The influence of long-term supplementation with biotin on the prevention of lameness in pasture fed dairy cows. J. Dairy Sci. 83:338-344.

Majee, D. N., E. C. Schwab, S. J. Bertics, W. M. Seymour, and R. D. Shaver. 2003. Lactation performance by dairy cows fed supplemental biotin and a B-vitamin blend. J. Dairy Sci. 86:2106-2112.

Midla, L. T., K. H. Hoblet, W. P. Weiss, and M. L. Moeschberger. 1998. Supplemental dietary biotin for prevention of lesions associated with aseptic subclinical laminitis (pododermatitis aseptica diffusa) in primiparous cows. Am. J. Vet. Res. 59:733-738.

Mock, D. M., C. L. Henrich-Shell, N. Carnell, P. Stumbo, and N. I. Mock. 2004. 3-Hydroxypropionic acid and methylcitric acid are not reliable indicators of marginal biotin deficiency in humans. J. Nutr. 134:317-320.

Mock, D. M., H. Jackson, G. L. Lankford, N. I. Mock, and S. T. Weintraub. 1989. Quantification of urinary 3-hydroxyisovaleric acid using deuterated 3-hydroxyisovaleric acid as internal standard. Biomed. Environ. Mass Spectrom. 18:652-656.

Mock, D. M., G. L. Lankford, and N. I. Mock. 1995. Biotin accounts for only half of the total avidin-binding substances in human serum. J. Nutr. 125:941-946.

Mock, D. M., N. I. Mock, and S. I. Stratton. 1997a. Concentrations of biotin metabolites in human milk. J. Pediatr. 131:456-458.

Mock, N. I., M. Malik, P. Stumbo, W. Bishop, and D. M. Mock. 1997b. Increased urinary excretion of 3-hydroxyisovaleric acid and decreased urinary excretion of biotin are sensitive early indicators of decreased status in experimental biotin deficiency. Am. J. Clin. Nutr. 65:951-958.

Mock, N. I., and D. M. Mock. 1992. Biotin deficiency in rats: Disturbances of leucine metabolism are detectable early. J. Nutr. 122:1493-1499.

NRC. 2001. Nutrient Requirements of Dairy Cattle. 7th rev. ed. National Academy Press, Washington, DC.

Palmquist, D. L., A. D. Beaulieu, and D. M. Barbano. 1993. Feed and animal factors influencing milk fat composition. J. Dairy Sci. 76:1753-1771.

Rerat, A., M. Fiszlewicz, A. Giusi, and P. Vaugelade. 1987. Influence of meal frequency on postprandial variations in the production and absorption of volatile fatty acids in the digestive tract of conscious pigs. J. Anim. Sci. 64:448-456.

Reynolds, C. K., G. B. Huntington, H. F. Tyrrell, and P. J. Reynolds. 1988. Net metabolism of volatile fatty acids, D- $\beta$-hydroxybutyrate, nonesterifield fatty acids, and blood gasses by portal-drained viscera and liver of lactating Holstein cows. J. Dairy Sci. 71:2395-2405. 
Rosendo, O., C. R. Staples, L. R. McDowell, R. McMahon, L. Badinga, F. G. Martin, J. F. Shearer, W. M. Seymour, and N. S. Wilkinson. 2004. Effects of biotin supplementation on peripartum performance and metabolites of Holstein cows. J. Dairy Sci. 87:25352545.

Sabourin, P. J., and L. L. Bieber. 1982. Purification and characterization of an $\alpha$-ketoisocaproate oxygenase of rat liver. J. Biol. Chem. 257:7460-7467.

Salmenpera, L., J. Perheentupa, J. P. Pispa, and M. A. Simmes. 1985. Biotin concentrations in maternal plasma and milk during prolonged lactation. Internat. J. Vit. Nutr. Res. 55:281-285.

SAS Institute. 2004. SAS/STAT User's Guide, Version 9. SAS Institute Inc., Cary, NC.

Scott, H. W., and B. A. Dehority. 1965. Vitamin requirements of several cellulolytic rumen bacteria. J. Bacteriol. 89:1169-1175.
Sukhija, P. S., and D. L. Palmquist. 1988. Rapid method for determination of total fatty acid content and composition of feedstuffs and feces. J. Agric. Food Chem. 36:1202-1206.

Tanaka, K., and K. J. Isselbacher. 1970. Experimental 3-hydroxyisovaleric aciduria induced by biotin deficiency. Lancet 296:930-931.

Truscott, R. J. W., C. J. Pullin, B. Halpern, J. Hammond, E. Haan, and D. M. Danks. 1979. The identification of 3-keto-2-methylvaleric acid and 3-hydroxy-2-methylvaleric acid in a patient with propionic acidemia. Biomed. Mass Spectrom. 6:294-300.

Weiss, W. P., and D. J. Wyatt. 2000. Effect of oil content and kernel processing of corn silage on digestibility and milk production by dairy cows. J. Dairy Sci. 83:351-358.

Zimmerly, C. A., and W. P. Weiss. 2001. Effects of supplemental biotin on performance of Holstein cows during early lactation. J. Dairy Sci. 84:498-506. 